\title{
A Distributed Plasticity Approach for Steel Frames Analysis Including Strain Hardening Effects
}

\author{
Andrius Grigusevičius¹, Gediminas Blaževičius ${ }^{1 *}$ \\ 1 Department of Applied Mechanics, Faculty of Civil Engineering, \\ Vilnius Gediminas Technical University, \\ Sauletekio al. 11, LT-10223 Vilnius, Lithuania \\ * Corresponding author, e-mail: gediminas.blazevicius@vgtu.It
}

Received: 08 October 2018, Accepted: 28 January 2019, Published online: 06 March 2019

\begin{abstract}
This paper focuses on the creation and numerical application of physically nonlinear plane steel frames analysis problems. The frames are analysed using finite elements with axial and bending deformations taken into account. Two nonlinear physical models are used and compared - linear hardening and ideal elastic-plastic. In the first model, distributions of plastic deformations along the elements and across the sections are taken into account. The proposed method allows for an exact determination of the stress-strain state of a rectangular section subjected to an arbitrary combination of bending moment and axial force. Development of plastic deformations in time and distribution along the length of elements are determined by dividing the structure (and loading) into the parts (increments) and determining the reduced modulus of elasticity for every part. The plastic hinge concept is used for the analysis based on the ideal elastic-plastic model. The created calculation algorithms have been fully implemented in a computer program. The numerical results of the two problems are presented in detail. Besides the stress-strain analysis, the described examples demonstrate how the accuracy of the results depends on the number of finite elements, on the number of load increments and on the physical material model. COMSOL finite element analysis software was used to compare the presented 1D FEM methodology to the 3D FEM mesh model analysis.
\end{abstract}

Keywords

reduced modulus of elasticity, distributed plasticity, incremental method, linear hardening, plastic deformations

\section{Introduction}

The material hardening phenomenon in steel structures has been widely discussed in theoretical and practical experimental based research $[1,2]$. It is commonly accepted that a piecewise linear hardening model properly represents an actual steel stress-strain relationship [3]. Plastic deformations in a structure, independent of a nonlinear material model, can be evaluated using several different approaches: using the concentrated plastic hinge theory $[4,5]$, defining semi-rigid connections [6], using the distributed plasticity approach [7] or by linearizing the nonlinear stress diagram of a cross section [8]. In most cases, especially when plasticity is 'concentrated' at the nodes, quite strict assumptions are made, which makes calculations relatively simple, nevertheless, the reliability of results may be insufficient.

In this paper the authors continue their previous research [17] on the non-linear stress-strain state in a cross section and its numerical application for steel frame analysis.
The main goal of the current research is to evaluate the distribution of plastic deformations along the length and in depth (across the sections) of the elements by dividing the structure into multiple finite elements and assigning them different moduli of elasticity in case of material linear hardening effect. The suggested methodology is new compared to previous researches [4-8] because it is based only on the fundamental equilibrium and compatibility equations, i.e. an equilibrium between internal and external forces is satisfied in any point of structure at any given time and the plane section assumption is valid. Because no other simplifications are made in the model and an incremental method [9] is used for the analysis of the problem, the computations are relatively complex (the computational cost of calculations is high) even in the case of a simple plane frame with uniaxial stress state in the cross sections. Nevertheless, authors suggest that this method allows for theoretically exact solution of linearly hardening 
bar structures. The authors chose to implement these calcu-lations in the Matlab environment [10], which will later allow them to incorporate it in the structural optimization problems [11-14] and [24-26] (which is the global goal of this research). This paper presents two numerical examples showing how the solutions are influenced by the number of finite elements and load increments used in the analysis. At the end, optimal values for these variables are suggested. In addition, the results of two material models (i.e. linear hardening and ideal elastic plastic) are compared.

\section{Main assumptions and physical material models}

The numerical algorithms for the analysis of steel frames in this paper are based on the following assumptions:

- plane sections remain plane after bending;

- plastic deformations are distributed along the length of the structural elements (in the case of the linear hardening model);

- a plastic hinge can be formed in any cross section (in the case of ideal elastic plasticity);

- the influence of bending moments and axial forces are taken into account in both - elastic and plastic material work stages;

- the influence of shear forces and tangential stress in the cross sections are ignored;

- the stability [15] of the structures and dynamic effects of loads are not considered

- deformations are small, i.e. equilibrium and compatibility equations are written for an undeformed structure;

Both the physical material models that are used in this paper can be shown in one stress-strain diagram (Fig. 1), which has three deformation paths - elastic (with elastic modulus $E$ ), elastic-plastic (with $E_{h}$ ), and ideally plastic (if $E_{h}=0$ ).

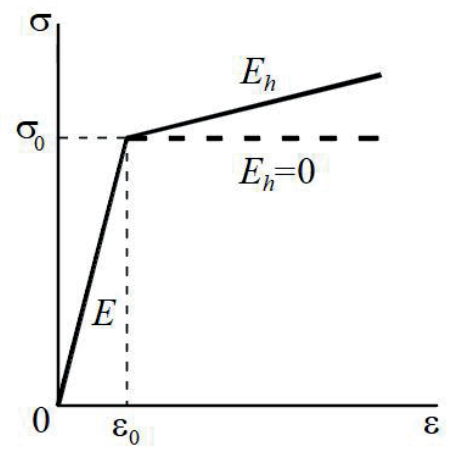

Fig. 1 Stress-strain diagrams of the linear hardening and ideal elastic plastic models

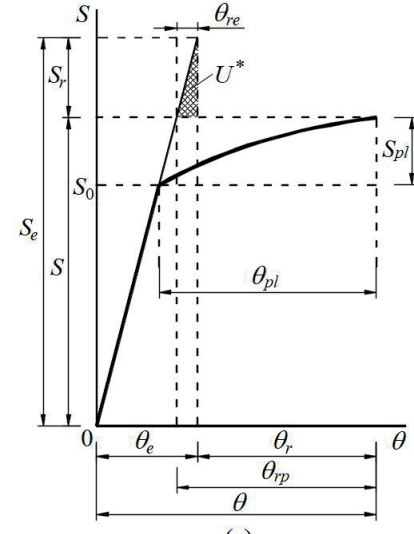

(a)

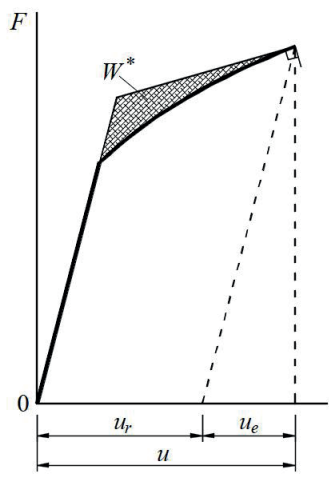

(b)
Fig. 2 (a) Relations between the internal forces and deformations and (b) between the loads and displacements

Stresses and strains of this diagram are related by the following equations:

$E=\frac{\sigma_{0}}{\varepsilon_{0}}$ and $E_{h}=\frac{\sigma-\sigma_{0}}{\varepsilon-\varepsilon_{0}}$,

$E_{h}$ - the modulus of elasticity in the second stage (linear hardening or ideal plasticity); $\sigma_{0}$ is the yield stress and $\varepsilon_{0}$ is the yield strain.

The elastic-plastic stage (when $\sigma>\sigma_{0}$ ) may be expressed in terms of the hardening ratio $\alpha$ :

$\sigma=\sigma_{0}+\alpha E\left(\varepsilon-\varepsilon_{0}\right)$

where $\alpha=E_{h} / E$ is the ratio between hardening and elastic moduli.

\section{Main equations and general problem formulation}

The stress state of a linearly hardening material is described by size $n$ vectors of the total internal forces $\boldsymbol{S}$, plastic internal forces $S_{p l}$, limit forces $S_{0}$, residual forces $\boldsymbol{S}_{r}$ and elastic forces $\boldsymbol{S}_{e}$ (Fig. 2a). In the elastic-plastic system, vectors $\boldsymbol{S}, \boldsymbol{S}_{e}$ and $\boldsymbol{S}_{r}$ are related as follows: $\boldsymbol{S}=\boldsymbol{S}_{e}+\boldsymbol{S}_{r}$.

The deformed state of a structure is defined by size $m$ vectors of the total displacements $\boldsymbol{u}$, residual displacements $\boldsymbol{u}_{r}$ and elastic displacements $\boldsymbol{u}_{e}$ (Fig. 2b), and size $n$ vectors of the total deformations $\boldsymbol{\theta}$, residual deformations $\boldsymbol{\theta}_{r}$ and elastic deformations $\boldsymbol{\theta}_{e}$. These quantities are related as follows: $\boldsymbol{u}=\boldsymbol{u}_{r}+\boldsymbol{u}_{e} ; \boldsymbol{\theta}=\boldsymbol{\theta}_{r}+\boldsymbol{\theta}_{e}$.

In addition, the residual deformations $\boldsymbol{\theta}_{r}$ are divided into two parts: the residual elastic $\boldsymbol{\theta}_{r e}$ and residual plastic $\boldsymbol{\theta}_{r p}$ deformations, thus $\boldsymbol{\theta}_{r}=\boldsymbol{\theta}_{r e}+\boldsymbol{\theta}_{r p}$. The residual internal forces are self-equilibrated, i.e. they satisfy the equilibrium equations:

$A S_{r}=0$, 
where $\boldsymbol{A}-$ is the equilibrium matrix $(m \times n)$. The elastic internal forces are directly related to the external forces (loads) $\boldsymbol{F}: \boldsymbol{A} \boldsymbol{S}_{e}=\boldsymbol{F}$. The residual displacements and residual deformations are compatible, i.e. they satisfy the compatibility equations: $\boldsymbol{A}^{T} \boldsymbol{u}_{r}=\boldsymbol{\theta}_{r}$.

In the elastic-plastic stress-strain states of the system, the internal forces and deformations are related through the flexibility matrix $\boldsymbol{D}$ and hardening matrix $\boldsymbol{H}$ :

$\boldsymbol{D} \boldsymbol{S}_{r}=\boldsymbol{\theta}_{r e}, \boldsymbol{H} \boldsymbol{\theta}_{r p}=\boldsymbol{S}_{p l}$.

The elastic solution is determined from:

$\boldsymbol{S}_{e}=\boldsymbol{D}^{-1} \boldsymbol{A}^{T}\left(\boldsymbol{A} \boldsymbol{D}^{-1} \boldsymbol{A}^{T}\right)^{-1} \boldsymbol{F}$.

The yield conditions for a structure may be written as follows:

$\boldsymbol{S}_{0}+\boldsymbol{H}\left(\boldsymbol{\theta}_{r p}^{+}+\boldsymbol{\theta}_{r p}^{-}\right)-\boldsymbol{\Phi}\left(\boldsymbol{S}_{e}+\boldsymbol{S}_{r}\right) \geq \mathbf{0}$,

where $\boldsymbol{\Phi}$ is the yield matrix; $\boldsymbol{\theta}_{r p}^{+}$is the vector of the only positive values of vector $\boldsymbol{\theta}_{r p}$ (non-positive values of vector $\boldsymbol{\theta}_{r p}$ are equated to zero); $\boldsymbol{\theta}_{r p}^{-}$is the vector of the only negative values of vector $\boldsymbol{\theta}_{r p}$ with the opposite signs (the negative signs are changed to positive and initially the non-negative values of vector $\boldsymbol{\theta}_{r p}$ are equated to zero). The last-mentioned vectors are related: $\boldsymbol{\theta}_{r p}=\boldsymbol{\theta}_{r p}^{+}-\boldsymbol{\theta}_{r p}^{-}$. Together, the Eqs. (3) and (6) define the domain of statically admissible solutions of the residual internal forces.

Static formulation of the problem, in the case when the relation between plastic internal forces and deformations is linear, was introduced by Čyras [16]. In this case, the classical extreme mechanics principle is used: of all statically admissible vectors of residual internal forces, the actual one corresponds to the minimum sum of complementary and potential plastic deformation energies.

The complementary deformation energy $U^{*}$ (Fig. 2a) is expressed as follows:

$U^{*}=\int_{\boldsymbol{\theta}_{e}-\boldsymbol{\theta}_{r e}}^{\boldsymbol{\theta}_{e}} \boldsymbol{S}_{r} d \theta=\frac{1}{2} \boldsymbol{S}_{r}^{T} \boldsymbol{D} \boldsymbol{S}_{r}$

In this paper the relation between plastic internal forces and deformations is nonlinear, therefore, the potential plastic deformation energy is expressed by the integral:

$U_{p l}=\int_{\boldsymbol{\theta}-\boldsymbol{\theta}_{p l}}^{\boldsymbol{\theta}} \boldsymbol{S}_{p l} d \boldsymbol{\theta}=\int_{\boldsymbol{\theta}-\boldsymbol{\theta}_{p l}}^{\boldsymbol{\theta}}\left(\boldsymbol{\theta}_{r p}^{+T}-\boldsymbol{\theta}_{r p}^{-T}\right) \boldsymbol{H} d \boldsymbol{\theta}$

Then the mathematical model of the problem stated on the basis of the above-mentioned principle reads: $\left(\frac{1}{2} \boldsymbol{S}_{r}^{T} \boldsymbol{D} \boldsymbol{S}+\int_{\boldsymbol{\theta}-\boldsymbol{\theta}_{p l}}^{\boldsymbol{\theta}}\left(\boldsymbol{\theta}_{p}^{+T}-\boldsymbol{\theta}_{r p}^{-T}\right) \boldsymbol{H} d \boldsymbol{\theta}\right) \rightarrow \min$,

$\boldsymbol{S}_{0}+\boldsymbol{H}\left(\boldsymbol{\theta}_{r p}^{+}+\boldsymbol{\theta}_{r p}\right)-\boldsymbol{\Phi}\left(\boldsymbol{S}_{e}+\boldsymbol{S}_{r}\right) \geq \mathbf{0}, \quad A \boldsymbol{S}_{r}=\mathbf{0}$,

$\boldsymbol{\theta}_{r p}^{+} \geq \mathbf{0}, \boldsymbol{\theta}_{r p}^{-} \geq \mathbf{0}$

The dual (kinematic) problem formulation reads:

$\left(-\frac{1}{2} \boldsymbol{S}_{r}^{T} \boldsymbol{D} \boldsymbol{S}_{r}+\int_{\boldsymbol{\theta}-\boldsymbol{\theta}_{p l}}^{\boldsymbol{\theta}}\left(\boldsymbol{\theta}_{r p}^{+T}-\boldsymbol{\theta}_{r p}^{-T}\right) \boldsymbol{H} d \boldsymbol{\theta}-\right.$

$-\left(\boldsymbol{\theta}_{r p}^{+T}-\boldsymbol{\theta}_{r p}^{-T}\right) \boldsymbol{H}\left(\boldsymbol{\theta}_{r p}^{+}-\boldsymbol{\theta}_{r p}^{-}\right)+$

$\left.+\left(\boldsymbol{\theta}_{r p}^{+T}-\boldsymbol{\theta}_{r p}^{-T}\right)\left(\boldsymbol{\Phi} \boldsymbol{S}_{e}-\boldsymbol{S}_{0}\right)\right) \rightarrow \max$

$\boldsymbol{D} \boldsymbol{S}_{r}+\boldsymbol{\Phi}^{T}\left(\boldsymbol{\theta}_{r p}^{+T}-\boldsymbol{\theta}_{r p}^{-T}\right)-\boldsymbol{A}^{T} \boldsymbol{u}_{r}=\mathbf{0}$

$\boldsymbol{\theta}_{r p}^{+} \geq \mathbf{0} ; \boldsymbol{\theta}_{r p}^{-} \geq \mathbf{0}$

The constraints (13)-(14) define the kinematically admissible distributions of the residual deformations and displacements. Equations (13) actually denote the compatibility between the residual deformations $\boldsymbol{\theta}_{r}$ and its components $\boldsymbol{\theta}_{r e}$ and $\boldsymbol{\theta}_{r p}$

It can be demonstrated that the objective function of the kinematic formulation (12) expresses the complementary work $W^{*}$ of the external loads (Fig. 2b). Thus, the problem (12)-(14) corresponds to the extreme energy principle: of all kinematically admissible vectors of residual displacements, the actual one corresponds to the maximum complementary work of external loads.

\section{Stress-strain state in a cross section of an element under bending and tension or compression} 4.1 Reduced modulus of elasticity

When physical nonlinearity is considered, the size and distribution of plastic deformations in a cross section is characterized by the multiple different parameters (the material properties $E_{h}$ and $E$; strains; elastic and plastic normal stresses; heights of plastic zones). It is convenient to define only one variable that would define all these parameters in an otherwise very complex analysis problem. In the current methodology, such a variable is $E_{r}$ - the reduced modulus of elasticity, which allows for the evaluating of the influence of $E_{h}$ and $E$ altogether (Fig. 3a). In replacing a cross section having $E_{h}$ and $E$ (Fig. $3 b$ ) with a section having the generalized $E_{r}$ (Fig. 3c), it is imperative to ensure that the distribution of the strains $\varepsilon$ remains the same. 


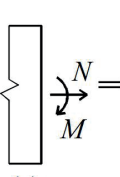

(a)

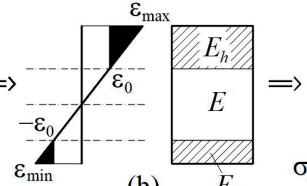

(b)

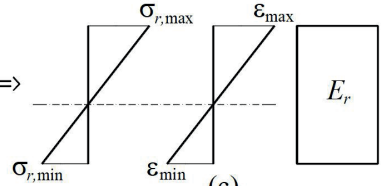

(c)
Fig. 3 (a) Internal forces in a cross section; (b) longitudinal strains, when two different moduli, $E_{h}$ and $E$ are considered; (c) normal stresses and longitudinal strains when one elastic modulus $E_{r}$ is considered

Therefore, the following equality must be satisfied:

$$
E_{r}=\frac{\sigma_{r, \max }-\sigma_{r, \min }}{\varepsilon_{\max }-\varepsilon_{\min }},
$$

where $\sigma_{r, \max }, \sigma_{r, \text { min }}$ are the values of normal stresses at the top and bottom of the cross section with the uniform elastic modulus (Fig. 3c); $\varepsilon_{\max }, \varepsilon_{\text {min }}$ are the longitudinal strains at the top and the bottom of the cross section (they have the same values in Fig. $3 b$ and c).

\subsection{Stress-strain state}

The internal forces $M$ and $N$ should be in equilibrium with the normal stresses $\sigma$ at every cross section:

$$
N=\int_{A} \sigma(y) d A, \quad M=\int_{A} y \sigma(y) d A,
$$

where $A$ is the cross section area; $y$ - the distance to the neutral axis of the cross section.

In addition, according to the classical mechanic's assumption of plane sections, every cross section must satisfy the equation:

$\kappa=-\frac{\varepsilon_{\max }-\varepsilon_{\min }}{h}$,

where $\kappa$ is the curvature and $h$ is the height of the cross section. Thus, using the Eqs. (2), (16) and (17) we can write the system of equations fully describing the relations between stresses, strains and internal forces. In this paper we will only show the stress-strain state definition for the case when both the bending moment and axial force are positive (the positive directions are shown in Fig. 3a). For example, for a rectangular cross section if normal stress is considered positive at the top $\sigma_{\max }<\sigma_{0}$ and negative at the bottom $-\sigma_{0}<\sigma_{\min }<0$ (III case in Fig. 4a), and $N<N_{\lim 3}$ (where $N_{\lim 3}$ is the third axial force limit, which together with the bending moment causes zero normal stress at the bottom of the cross section $\sigma_{\min }=0$ ) there are seven equations to be written:

$$
\begin{aligned}
& 0.5 b h_{e l 1} \sigma_{\min }+0.5 b \sigma_{0} h_{e l 2}+b \sigma_{0} h_{p l}+ \\
& 0.5 b\left(\sigma_{\max }-\sigma_{0}\right) h_{p l}=N, \\
& -\frac{1}{3} b \sigma_{\min } h_{e l 1}^{2}+\frac{1}{3} b \sigma_{0} h_{e l 2}^{2}+b \sigma_{0} h_{p l}\left(0.5 h_{p l}+h_{e l 2}\right)+ \\
& 0.5 b\left(\sigma_{\max }-\sigma_{0}\right) h_{p l}\left(\frac{2}{3} h_{p l}+h_{e l 2}\right)=M-N y_{0}, \\
& \sigma_{0}-\alpha \sigma_{0}+E_{h} \kappa\left(y_{0}-0.5 h\right)=\sigma_{\max }, \\
& E \kappa\left(y_{0}+0.5 h\right)=\sigma_{\min },-E \kappa h_{e l 2}=\sigma_{0}, \\
& y_{0}+0.5 h=h_{e l 1}, 0.5 h-y_{0}-h_{e l 2}=h_{p l} .
\end{aligned}
$$

In this system, Eq. (18) defines the equilibrium of forces perpendicular to the plane of the cross section; equation (19) defines the equilibrium of bending moments in respect to the neutral axis. Equations (20) relate stresses and curvature in different zones of the cross section (taking into account the 'plane sections' assumption (17) and Eq. (2)). Equations (21) relate to the heights of elastic deformations zones $h_{e l 1}, h_{e l 2}$, the height of plastic deformations zone $h_{p l}$ and the ordinate of neutral axis $y_{0}$. For a more detailed explanation of these equations refer to [17].

The seven equation system (18)-(21) can be mathematically simplified to:

$$
\bar{a} \kappa^{2} y_{0}^{2}+\bar{b} \kappa^{2} y_{0}+\bar{c} \kappa^{2}+\bar{d} \kappa y_{0}+\bar{e} \kappa+\bar{f}=0,
$$

Table 1 Equations for determining four axial force limits (Fig. 4b) of a rectangular cross section

\begin{tabular}{ccc}
\hline Axial force limits & Nonlinear equation & Coefficients of the nonlinear equation \\
\hline$N_{\lim 1}=\frac{6\left(M_{0}-M\right)}{h}$ & - & - \\
$N_{\lim 2}=\sigma_{0} b\left(h-h_{e l}+\alpha\left(\frac{h^{2}}{h_{e l}}-2 h+h_{e l}\right)\right)$ & $\bar{a} h_{e l}^{3}+\bar{b} h_{e l}^{2}+\bar{c} h_{e l}-\bar{d}=0$ & $\bar{a}=2 \sigma_{0} b(1-\alpha) ; \bar{b}=3 \sigma_{0} b h(\alpha-1) ; \bar{c}=6 M ;$ \\
$N_{\lim 3}=\sigma_{0} b\left(h-0.5 h_{e l}+\alpha\left(\frac{h^{2}}{2 h_{e l}}-h+0.5 h_{e l}\right)\right)$ & $-\bar{d}=\alpha \sigma_{0} b h^{3}$ \\
$N_{\lim 4}=\sigma_{0} b h+\frac{6 M}{h}$ & - & $\bar{a}=\sigma_{0} b(1-\alpha) ; \bar{b}=1.5 \sigma_{0} b h(\alpha-1) ; \bar{c}=6 M ;$ \\
$\bar{d}$ & $-0.5 \alpha \sigma_{0} b h^{3}$ & - \\
\hline
\end{tabular}


$\bar{g} \kappa^{3} y_{0}^{3}+\bar{h} \kappa^{3} y_{0}^{2}+\bar{i} \kappa^{3} y_{0}+\bar{j} \kappa^{2} y_{0}^{2}+\bar{k} \kappa^{3}+$

$\bar{l} \kappa^{2} y_{0}+\bar{m} \kappa^{2}+\bar{n}=0$,

where $\bar{a}, \bar{b}, \ldots \bar{n}$ are the coefficients of the nonlinear equations (Table 5). All possible stress-strain states (see Table 5 in Appendix A and Fig. 4a) and axial force limits (Table 1 and Fig. 4b) are explained in detail in [17].

Table 2 allows the determination of which combination of stress-strain state variations is to be used for a particular cross section subjected to the bending moment and axial force. This table shows all possible combinations of the stress-strain states and axial force limits when the axial force increases and the bending moment remains constant. In advance of using Table 2, the axial force limits have to be calculated according to Table 1. Then, following the ascending order of the axial force limits' values and the value of the particular axial force under consideration, the necessary stress-strain state is determined from Table 2 and the corresponding system of equations - from Table 5 (Appendix A). For example, let's say that the bending moment $M$ is smaller than $M_{0}$ and the equations of Table 1 yields two real values of $N_{\lim 2}$, three of $N_{\lim 3}$, one of $N_{\lim 1}$ and one of $N_{\lim 4}$. Let's say that all these values and the value of the given axial force lie in the following order $N_{\lim 1}<N_{\lim 3}^{a}<N_{\lim 3}^{b}<N_{\lim 2}^{a}<N_{\lim 2}^{b}<N<N_{\lim 3}^{c}<N_{\lim 4}$. Table 2 indicates that this order corresponds to 'Combination VI' and the position of the axial force $N$ indicates the use of the third stress-strain state equations for the analysis.
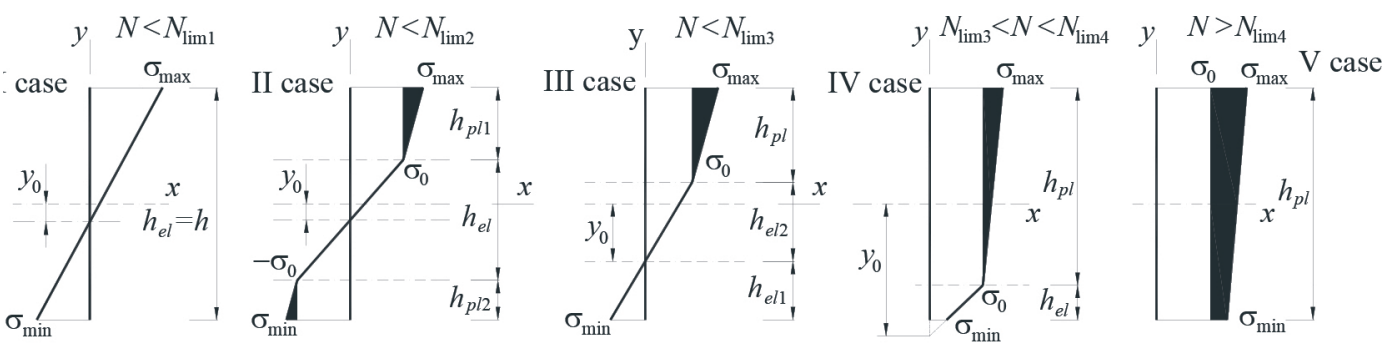

(a)
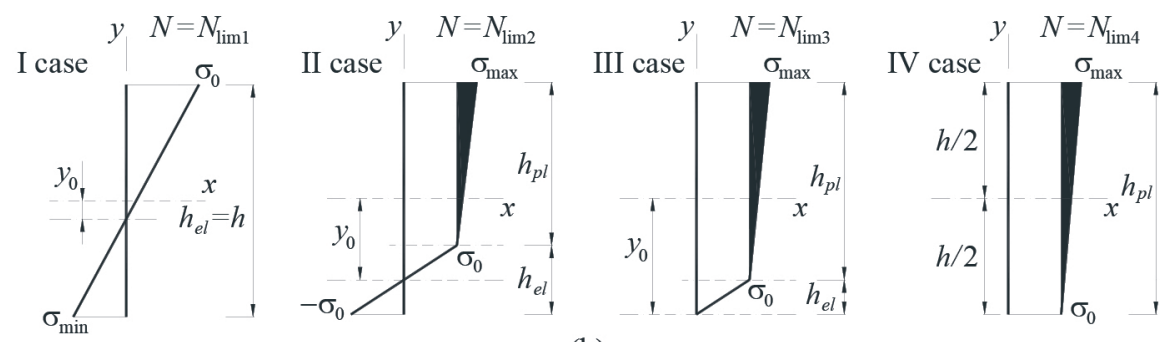

(b)

Fig. 4 Nine stress-strain states of a rectangular cross section when (a) $N \neq N_{\lim }$ and when (b) $N=N_{\lim }$

Table 2 Combinations of stress-strain states variations in a rectangular cross section when the axial force is gradually increasing

\begin{tabular}{|c|c|c|c|c|c|c|c|c|c|c|c|c|c|c|c|c|}
\hline 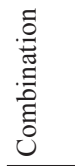 & 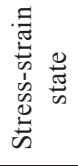 & $z^{\equiv}$ & 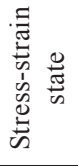 & $z^{\equiv}$ & 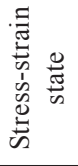 & $z^{\Xi}$ & 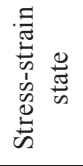 & $z^{\Xi}$ & 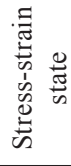 & $z^{\underline{\Xi}}$ & 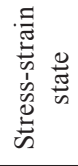 & $z^{\Xi}$ & 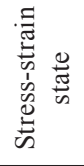 & $z^{\Xi}$ & 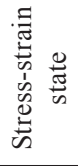 & 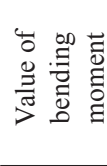 \\
\hline I & $1 \mathrm{st}$ & 1 & 4th & 4 & 5 th & - & - & - & - & - & - & - & - & - & - & $M<M_{0}$ \\
\hline II & $1 \mathrm{st}$ & 1 & $3 \mathrm{rd}$ & 3 & 4th & 4 & 5 th & - & - & - & - & - & - & - & - & $M<M_{0}$ \\
\hline III & $1 \mathrm{st}$ & 1 & 4th & $3^{\mathrm{a}}$ & $3 \mathrm{rd}$ & $3^{\mathrm{b}}$ & 4 th & 4 & 5 th & - & - & - & - & - & - & $M<M_{0}$ \\
\hline IV & $1 \mathrm{st}$ & 1 & 4th & $3^{\mathrm{a}}$ & $3 \mathrm{rd}$ & $2^{\mathrm{a}}$ & 2 nd & $2^{\mathrm{b}}$ & $3 \mathrm{rd}$ & $3^{\mathrm{b}}$ & 4th & 4 & 5th & - & - & $M<M_{0}$ \\
\hline $\mathrm{V}$ & $1 \mathrm{st}$ & 1 & $3 \mathrm{rd}$ & $3^{\mathrm{a}}$ & 4th & $3^{\mathrm{b}}$ & $3 \mathrm{rd}$ & $3^{\mathrm{c}}$ & 4th & 4 & 5 th & - & - & - & - & $M<M_{0}$ \\
\hline VI & $1 \mathrm{st}$ & 1 & $3 \mathrm{rd}$ & $3^{\mathrm{a}}$ & 4 th & $3^{\mathrm{b}}$ & $3 \mathrm{rd}$ & $2^{\mathrm{a}}$ & $2 \mathrm{nd}$ & $2^{\mathrm{b}}$ & $3 \mathrm{rd}$ & $3^{c}$ & 4th & 4 & 5th & $M<M_{0}$ \\
\hline VII & $1 \mathrm{st}$ & 1 & $3 \mathrm{rd}$ & $2^{\mathrm{a}}$ & 2nd & $2^{\mathrm{b}}$ & $3 \mathrm{rd}$ & 3 & 4 th & 4 & 5th & - & - & - & - & $M<M_{0}$ \\
\hline VIII & - & 2 & $3 \mathrm{rd}$ & 3 & 4th & 4 & $3 \mathrm{rd}$ & - & - & - & - & - & - & - & - & $M=M_{0}$ \\
\hline IX & - & $2^{\mathrm{a}}$ & $3 \mathrm{rd}$ & $2^{b}$ & 2nd & $2^{\mathrm{c}}$ & $3 \mathrm{rd}$ & 3 & 4 th & 4 & 5 th & - & - & - & - & $M=M_{0}$ \\
\hline$X$ & 2 nd & 2 & $3 \mathrm{rd}$ & 3 & 4th & 4 & 5th & - & - & - & - & - & - & - & - & $M>M_{0}$ \\
\hline XI & 2nd & $2^{\mathrm{a}}$ & $3 \mathrm{rd}$ & $2^{\mathrm{b}}$ & 2nd & $2^{\mathrm{c}}$ & $3 \mathrm{rd}$ & 3 & 4th & 4 & 5th & - & - & - & - & $M>M_{0}$ \\
\hline
\end{tabular}




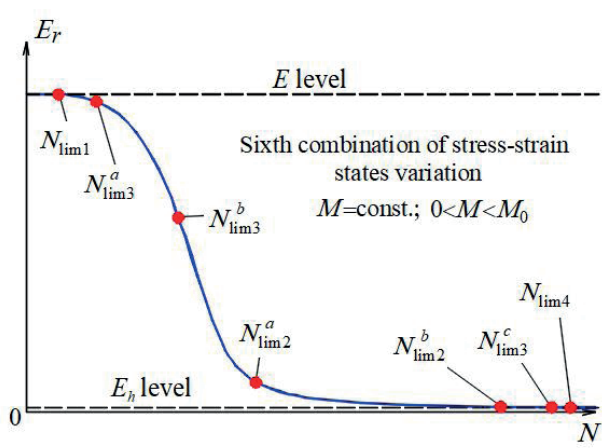

(a)

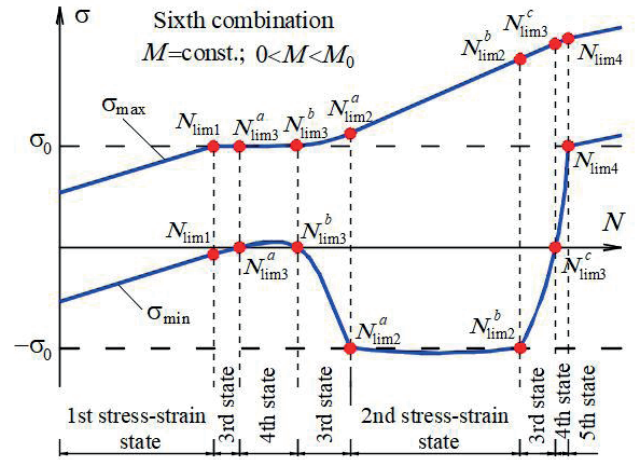

(b)

Fig. 5 (a) Typical variations of the reduced modulus of elasticity $E_{r}$ and (b) normal stresses at the top layer $\sigma_{\max }$ and the bottom layer $\sigma_{\min }$ of a cross section while the axial force increases

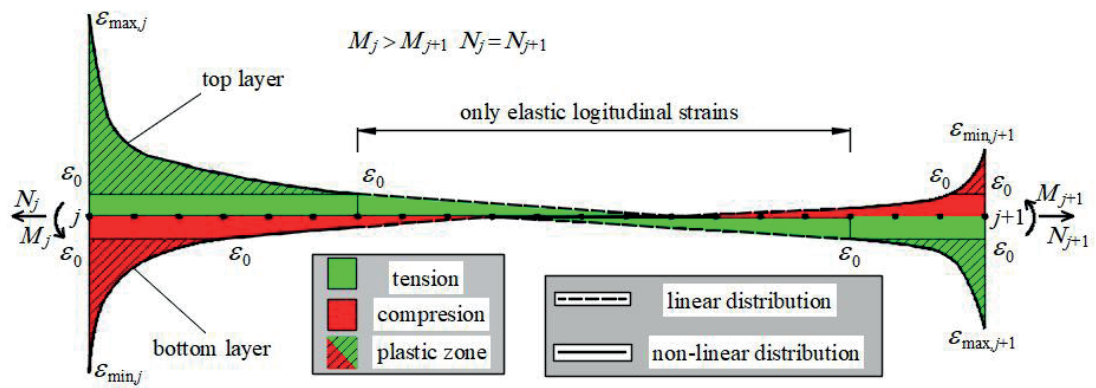

(a)

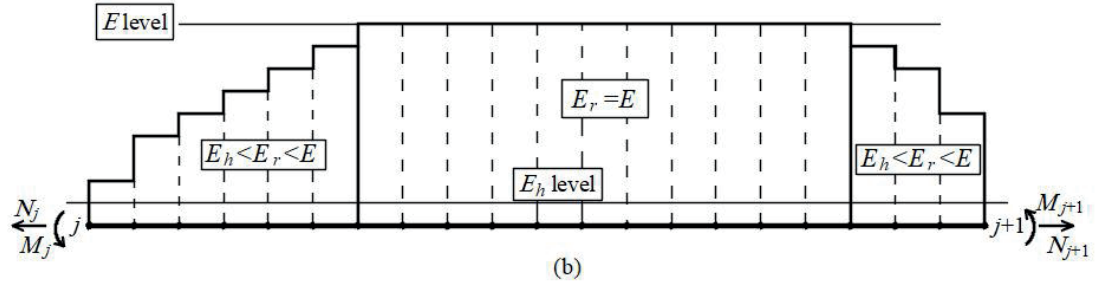

Fig. 6 A structural element divided into finite elements: (a) characteristic nonlinear distribution of longitudinal strains; (b) distribution of the reduced moduli of elasticity $E$

Fig. 5 shows three variation curves of the unknowns when stress-strain states and axial force limits change according to 'Combination VI' of Table 2 (all curves are drawn from repetitive analysis when $N$ increases and $M$ $=$ const.). It is worth mentioning that normal stress at the bottom of the cross section $\sigma_{\min }$ has a general tendency to decrease in a particular part of the loading curve although the axial force constantly increases (Fig. 5b).

\section{Strain distribution along the length of an element}

The procedure described in section 4 allows the determination of the stress-strain state at any point of an element $k$. A typical nonlinear distribution of longitudinal strains in the bottom and top layers of a cross section determined from internal forces at multiple points of an element is shown in Fig. 6. Distribution of the plastic strains along the length of a structural element can be determined with reasonable precision by dividing it into $r_{k}$ finite elements. Naturally, the solution converges to an 'exact' one if $r_{k} \rightarrow \infty$. In the current methodology we evaluate the plastic zone of every cross section through the reduced modulus of elasticity $E_{r}$. A typical distribution of $E_{r}$ among the chosen number of finite elements is shown in Fig. 6 b.

\section{Development of plastic strains}

If the load increases in an elastic-plastic structure, then at some point plastic strains start to develop. If, from that instant, the load is increased by the increment $\Delta F$, then the stiffness of the structure starts to change - it reduces. Therefore, in contrast to an elastic system, a one load iteration is not sufficient to solve an analysis problem when a physically nonlinear material is evaluated. The loading must be divided into increments [9] - usually equal parts $-\Delta F^{f}$, $f=1,2, \ldots, t$ where $t$ is the number of load increments. Natu- 
rally, the accuracy of the results increases if the load increments are smaller. During a one load increment the bending moment and axial force increase, but while the variation of the bending moment within the element is changing, the axial force usually remains constant over the element length.

A reduction of element stiffness can be expressed in terms of the reduced modulus of elasticity $E_{r}$, which (in plastic state) changes over the element length $l_{k}$ as well as over the load increment $\Delta F^{f}$, making the two-way nonlinear variation surface (Fig. 7a). In the proposed incremental analysis, it is important to determine the average value of this nonlinear surface as precisely as possible. For an approximate analysis the middle point value of $E_{r}$ may be accurate enough (Fig. 7a):

$E_{r, k}^{f}=E_{r \operatorname{mid}, k}^{f^{\prime}}$.

However, the exact value of $E_{r, k}^{f}$ is slightly higher. According to the increase of $E_{r}$ values over the element length (Fig. 7b) and over the load increment (Fig. 7c) $E_{r, k}^{f}$ may be expressed in terms of the nine perimeter values of $E_{r}$ :

$$
\begin{aligned}
& E_{r, k}^{f}=0,25 \psi^{2}\left(E_{r \max , k}^{(f-1)}+E_{r \min , k}^{(f-1)}+E_{r \max , k}^{f}+E_{r \min , k}^{f}\right)- \\
& -0,5 \psi^{2}\left(E_{r \operatorname{mid}, k}^{f}+E_{r \operatorname{mid}, k}^{(f-1)}+E_{r \max , k}^{f^{\prime}}+E_{r \min , k}^{f^{\prime}}-2 E_{r \operatorname{mid}, k}^{f^{\prime}}\right)+ \\
& +0,5 \psi\left(E_{r \operatorname{mid}, k}^{f}+E_{r \operatorname{mid}, k}^{(f-1)}+E_{r \max , k}^{f^{\prime}}+E_{r \min , k}^{f^{\prime}}-4 E_{r \operatorname{mid}, k}^{f^{\prime}}\right)+E_{r \operatorname{mid}, k}^{f^{\prime}} .
\end{aligned}
$$

The multiple numerical experiments performed by the authors of this paper for the determination of the value $\psi$ showed that generally $\psi=1 / 3$ and even for relatively complex functions $\psi=1 / 3$. In the latter case, it was observed that if the interval of the perimeter values decreases, then $\psi$ converges to an exact value of $1 / 3$. Therefore, it can be generally assumed that if $l_{k} \rightarrow 0$ and $\Delta F \rightarrow 0$, then $\psi \rightarrow 1 / 3$, i.e. the accuracy of the solution increases if the numbers of the finite elements and load increments are increased. If $\psi=0$, Eq. (25) becomes a simplified version for the approximate analysis: $E_{r, k}^{f}=E_{r \operatorname{mid}, k}^{f^{\prime}}$.

\section{Mathematical models and solution algorithms}

\subsection{Linear hardening material model}

Let the structure be additionally divided into $\bar{k}=1,2, \ldots, \bar{r}$ finite elements and the load $\boldsymbol{F}$ divided into a set of the equal increments $\Delta \boldsymbol{F}^{f} ; f=1,2, \ldots, t$. Then a classical mathematical model for elastic frame analysis consisting of equilibrium, compatibility and constitutive equations can be adapted for an analysis of a physically nonlinear frame:

$\boldsymbol{A} \Delta \boldsymbol{S}^{f}=\Delta \boldsymbol{F}^{f}$,

$\boldsymbol{A}^{T} \Delta \boldsymbol{u}^{f}-\boldsymbol{Z} \Delta \boldsymbol{\varepsilon}^{f}=\mathbf{0}$,

$\boldsymbol{D}_{\varepsilon}^{f} \Delta \boldsymbol{S}^{f}-\Delta \boldsymbol{\varepsilon}^{f}=\mathbf{0}, f=1,2, \ldots, t$,

where $\boldsymbol{A}$ is the equilibrium matrix; $\boldsymbol{Z}=\operatorname{diag} \boldsymbol{Z}_{\bar{k}}$ and $\boldsymbol{D}_{\varepsilon}^{f}=\operatorname{diag} \boldsymbol{D}_{\varepsilon, \bar{k}}^{f}$ are the block-diagonal matrices of an entire structure consisting of the individual blocks for every element $-\boldsymbol{Z}_{\bar{k}}$ and $\boldsymbol{D}_{\varepsilon, \bar{k}}^{f} ; \Delta \boldsymbol{S}^{f}, \Delta \boldsymbol{u}^{f}$ and $\Delta \boldsymbol{\varepsilon}^{f}$ are the vectors of the increments of internal forces, displacements and longitudinal strains. The system of Eqs. (26)-(28) can be expressed in terms of displacements:

$\boldsymbol{K}^{f} \Delta \boldsymbol{u}^{f}=\Delta \boldsymbol{F}^{f}$

where $\boldsymbol{K}^{f}=\boldsymbol{A}\left(\boldsymbol{Z} \boldsymbol{D}_{\varepsilon}^{f}\right)^{-1} \boldsymbol{A}^{T}$ is the stiffness matrix of the structure during $f$-th load increment. The matrix $\boldsymbol{Z}_{\bar{k}}$ of an individual finite element defines the known relation between the increments of deformations $\Delta \boldsymbol{\theta}_{\bar{k}}^{f}$ and increments of longitudinal strains $\Delta \varepsilon_{\frac{k}{k}}^{f}$ :

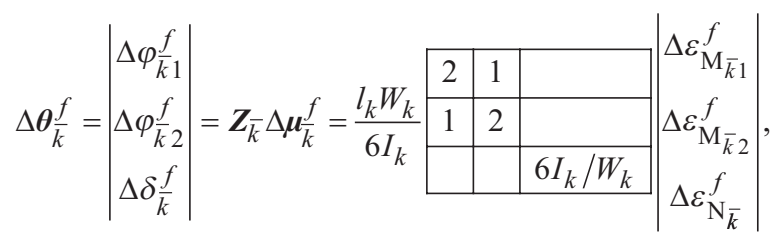

where $\Delta \varepsilon_{\mathrm{M}_{\bar{k} 1}}^{f}, \Delta \varepsilon_{\mathrm{M}_{\bar{k} 2}}^{f}$ are the increments of maximum longitudinal strains due to the increments of bending moments in the corresponding element nodes; $\Delta \varepsilon_{\mathrm{N}_{\bar{k}}}^{f}$ - the increment of

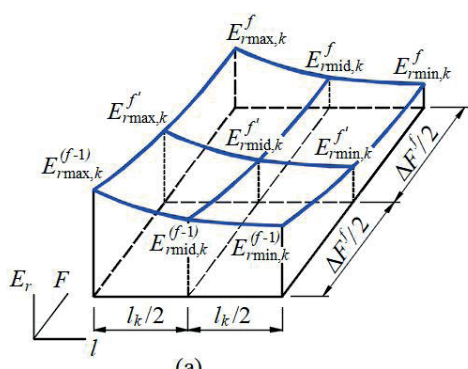

(a)

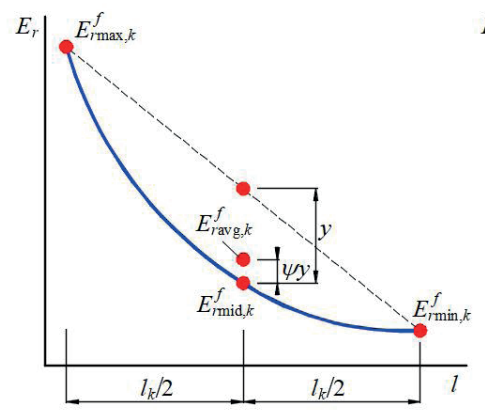

(b)

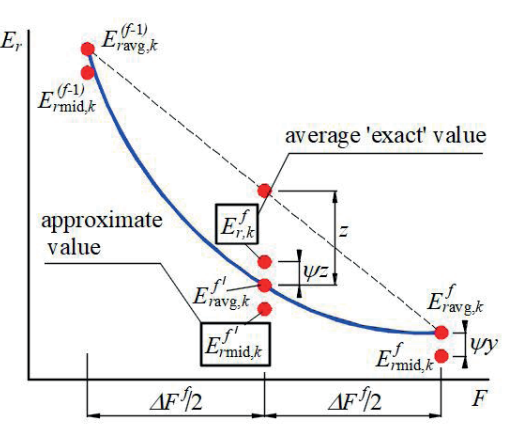

(c)

Fig. 7 Determination of an average value of reduced modulus of elasticity 
maximum longitudinal strain due to the increment of axial force; $\Delta \varphi_{\frac{f}{k} 1}^{f}, \Delta \varphi \frac{f}{k 2}$ - the increments of rotations in element nodes; $\Delta \delta_{\bar{k}}^{f}-$ the increment of element elongation.

The matrix $\boldsymbol{D}_{\varepsilon, \bar{k}}^{f}$ of every individual element depends on the stress state reached in the previous load increment. This matrix defines the known relation between the increments of longitudinal strains $\Delta \varepsilon \frac{f}{k}$ and increments of internal forces $\Delta S^{f}$ :

$$
\Delta \boldsymbol{\mu}_{\bar{k}}^{f}=\boldsymbol{D}_{\varepsilon, \bar{k}}^{f} \Delta S_{\bar{k}}^{f}=\frac{1}{E_{r, \bar{k}}^{f} W_{\bar{k}}} \begin{array}{|l|l|l|l|}
\hline 1 & & \\
\hline & 1 & \\
\hline & & W_{\bar{k}} / A_{\bar{k}} \\
\hline
\end{array} \cdot\left|\begin{array}{c}
\Delta M_{\bar{k} 1}^{f} \\
\Delta M_{\bar{k} 2}^{f} \\
\Delta N_{\bar{k}}^{f}
\end{array}\right|
$$

where $E_{r, \bar{k}}^{f}$ is the reduced modulus of elasticity determined according to Eqs. (24) or (25). In every step of the iterative analysis process (Fig. 8) this modulus has to be determined for every plastically deformed finite element.

For example, let's say that for the $f$-th load increment $E_{r, \bar{k}}^{f}=E_{r, \bar{k}}^{(f-1)}$. Every external iteration begins with the first internal iteration $-p=1$, i.e. $E_{r, \bar{k}}^{f, p}=E_{r, \bar{k}}^{f, 1}$ and problem (26)(28) is solved. The internal forces determined in this internal iteration allows for the calculating of a new reduced modulus of elasticity $E_{r, \bar{k}}^{f, 2}$ and the solving of problem (26)-(28) again. Internal iterations are continued while the relation $\left|E_{r, \bar{k}}^{f, p}-E_{r, \bar{k}}^{f,(p-1)}\right| / E_{r, \bar{k}}^{f, p}$ becomes smaller than the determined convergence tolerance $\lambda$. The last internal iteration number

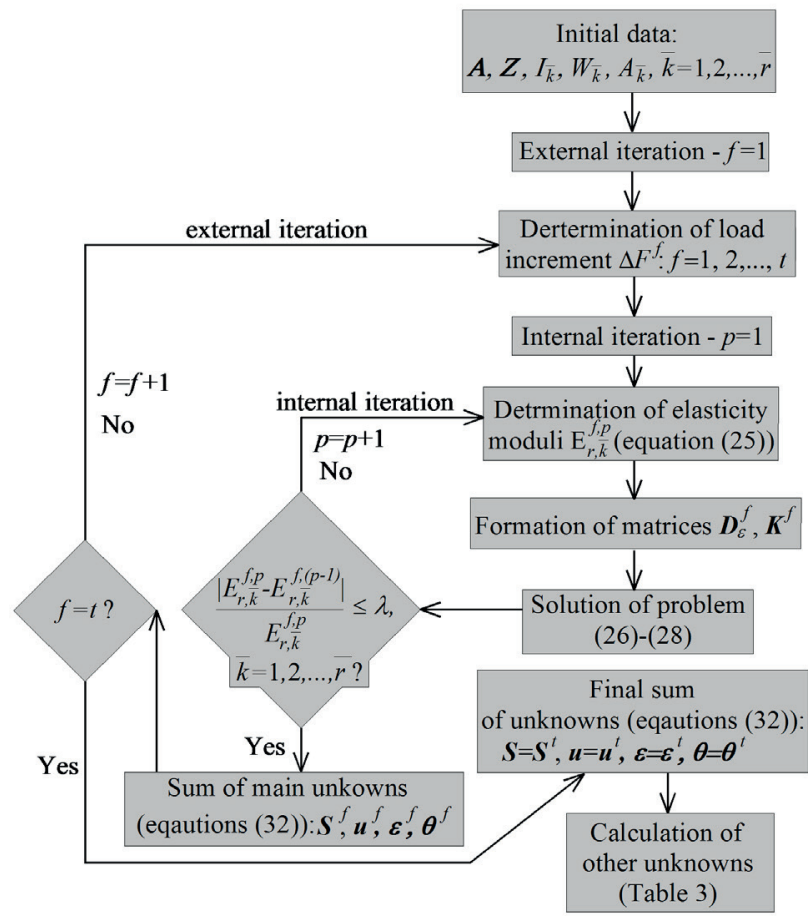

Fig. 8 Block scheme of analysis problem is indicated as $v$, while the last value of $E_{r}$ is carried to the first internal iteration of the next external iteration $(f+1)$. Fig. 9 shows the sequence of internal and external iterations used to determine $E_{r}$ in the $F-u_{i}$ diagram.

When all load increments are evaluated, the total values of the unknowns are determined by combining the contributions of all $t$ iterations:

$\boldsymbol{u}=\sum_{f=1}^{t} \Delta \boldsymbol{u}^{f} ; \boldsymbol{S}=\sum_{f=1}^{t} \Delta \boldsymbol{S}^{f} ; \boldsymbol{\mu}=\sum_{f=1}^{t} \Delta \boldsymbol{\mu}^{f} ; \boldsymbol{\theta}=\sum_{f=1}^{t} \Delta \boldsymbol{\theta}^{f}$

If the total displacements, internal forces, strains and deformations are determined, all other parameters of the stress-strain state in the structure may be readily calculated. The equations for several more important parameters are given in Table 3.

\subsection{Ideal elastic plastic material model}

If all quantities associated with the plastic deformations $\boldsymbol{\theta}_{r p}^{+}$and $\boldsymbol{\theta}_{r p}^{-}$are eliminated from model (9)-(11), it becomes a classical analysis problem formulation for a structure of elastic perfectly plastic material [21-22]:

$\frac{1}{2} \boldsymbol{S}_{r}^{T} \boldsymbol{D} \boldsymbol{S}_{r} \rightarrow \min$,

$f\left(\boldsymbol{S}_{e}+\boldsymbol{S}_{r}\right) \leq \boldsymbol{S}_{0}$,

$A \boldsymbol{S}_{r}=\mathbf{0}$,

where the yield conditions (34) combines the nonlinear yield conditions of every section expressed in terms of the residual $S_{r}$ and elastic $S_{e}$ internal forces. For rectangular sections these conditions for every section are [21]:

$\left|M_{e, j}+M_{r, j}\right| M_{0, j}+\frac{h_{j}^{2}}{16}\left|N_{e, j}+N_{r, j}\right|^{2} \leq M_{0, j}^{2} \cdot$

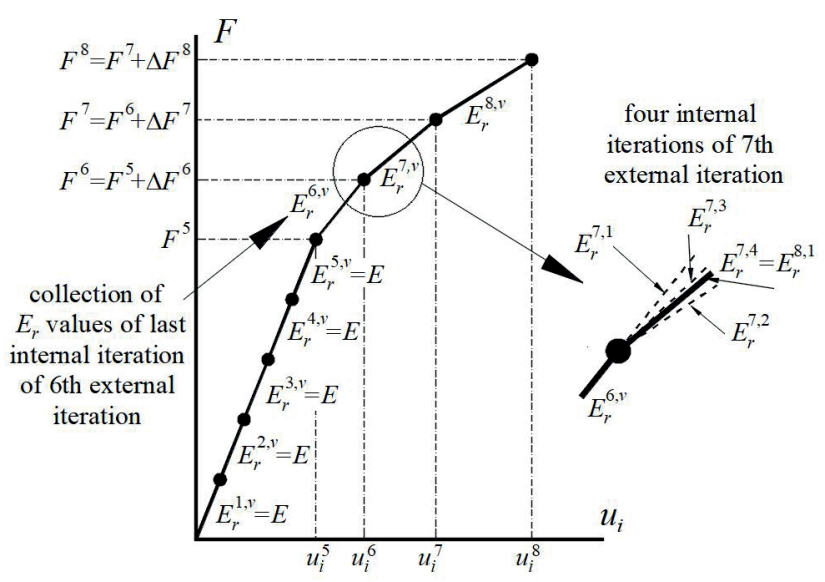

Fig. 9 Characteristic nonlinear force-displacement diagram and reduced modulus of elasticity $E_{r}$ in external and internal iterations 
Table 3 Equations for determining the parameters of a structure and cross sections

\begin{tabular}{|c|c|}
\hline Unknowns of a section $\mathrm{j}$ & Equations* \\
\hline Maximum longitudinal strains (at the top and bottom of a section) & $\varepsilon_{\max , j}=\varepsilon_{M, j}+\varepsilon_{N, j} ; \varepsilon_{\min , j}=-\varepsilon_{M, j}+\varepsilon_{N, j}$ \\
\hline Maximum stress & $\sigma_{\max , j}=\sigma_{0}+\left(\varepsilon_{\max , j}-\varepsilon_{0}\right) E_{h} ; \sigma_{\min , j}=-\sigma_{0}+\left(\varepsilon_{\min , j}-\varepsilon_{0}\right) E_{h}$ \\
\hline Heights of plastic and elastic zones & $\begin{array}{c}h_{p l 1, j}=h_{j} \frac{\varepsilon_{\max , j}-\varepsilon_{0}}{\varepsilon_{\max , j}-\varepsilon_{\min , j}} ; h_{p l 2, j}=h_{j} \frac{-\varepsilon_{\min , j}-\varepsilon_{0}}{\varepsilon_{\max , j}-\varepsilon_{\min , j}} \\
h_{e l, j}=h_{j}-h_{p l 1, j}-h_{p l 2, j}\end{array}$ \\
\hline Curvature & $\kappa_{j}=\frac{\varepsilon_{\min , j}-\varepsilon_{\max , j}}{h_{j}}$ \\
\hline Ordinate of the neutral axis & $y_{0, j}=h_{j}\left(0,5-\frac{\varepsilon_{\max , j}}{\varepsilon_{\max , j}-\varepsilon_{\min , j}}\right)$ \\
\hline Unknowns of a structure & Equations \\
\hline Elastic and residual displacements & $\boldsymbol{u}_{e}=\left(\boldsymbol{A} \boldsymbol{D}^{-1} \boldsymbol{A}^{T}\right)^{-1} \boldsymbol{F} ; \boldsymbol{u}_{r}=\boldsymbol{u}-\boldsymbol{u}_{e}$ \\
\hline Elastic and residual internal forces & $\boldsymbol{S}_{e}=\boldsymbol{D}^{-1} \boldsymbol{A}^{T} \boldsymbol{u}_{e} ; \boldsymbol{S}_{r}=\boldsymbol{S}-\boldsymbol{S}_{e}$ \\
\hline
\end{tabular}

* these equations are valid only for the second limit state (see second scheme of Fig. 5a) if $\sigma_{\max }>\sigma_{0}>0$ and $\sigma_{\min }<-\sigma_{0}<0$. Equations for other states can be easily derived and are not shown here for brevity.

\section{Numerical examples and discussions}

All described algorithms were numerically implemented with MATLAB software.

\subsection{Example 1}

This example is dedicated to the numerical implementation of the analysis problem algorithm (Fig. 8) and investigation into how the number of finite elements and the number of force increments influence the accuracy of results. All force increments are chosen to be equal. In addition, the influence of the coefficient $\psi$ to the accuracy of results is analyzed (if $\psi=1 / 3$, calculations are 'exact' and if $\psi=0-$ 'approximate'). The steel beam (Fig. 10a) of rectangular cross section is considered $-h \times b=0.3 \mathrm{~m} \times$ $0.1 \mathrm{~m}, E=205 \mathrm{GPa}, E_{h}=E / 50, \sigma_{0}=235 \mathrm{MPa}$. Two types of finite elements are used: with and without distributed load [21,23]. Internal iterations of the analysis problem are stopped when the change of all $E_{r}$ values is smaller than $0.1 \%(\lambda=0.001)$. Calculations have been performed for several values of the finite element number $r_{k}$ and load increments number $t$. It should be noted that the maximum value of stress reached in the beam $\left(\sigma_{\max } \cong 389 \mathrm{MPa}\right.$, see Table 4) well exceeds the limit of the steel strength, in addition geometrical non-linearity is not evaluated and therefore this is a theoretical problem just to test the algorithm. The case of analysis, when $r_{1}=r_{2}=t=256$ can be considered as the most accurate or almost absolutely accurate. However, the computational time to solve it is unacceptably long - it takes around 17 hours on an average
PC. Fig. 12 and Table 4 shows that relatively good results (accuracy of $\sim(1-2) \%$ ) can be achieved if $r_{k}$ and $t$ are equal to 16 or 32. Other significant results - the plastic internal forces, distributions of plastic zones - are shown in Figs. $10 \mathrm{~b}$ and 11.

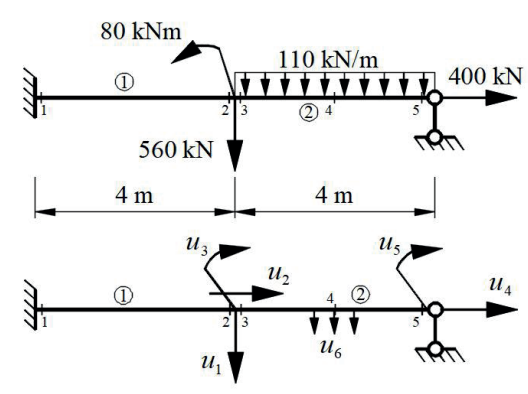

(a)

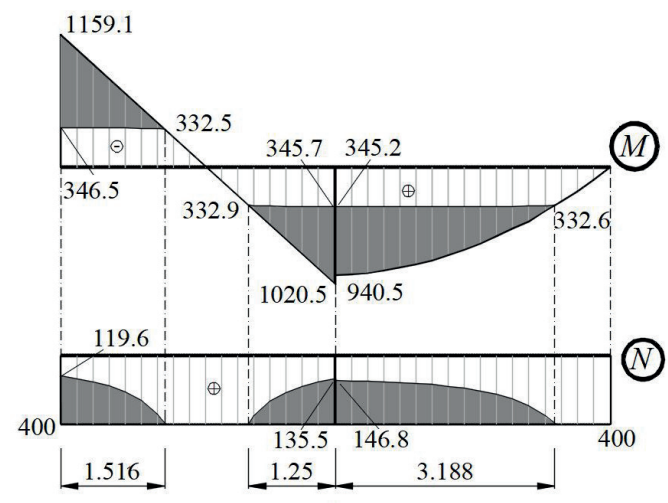

(b)

Fig. 10 (a) Scheme and discrete model of the beam; (b) total and plastic internal forces and plastic zones 


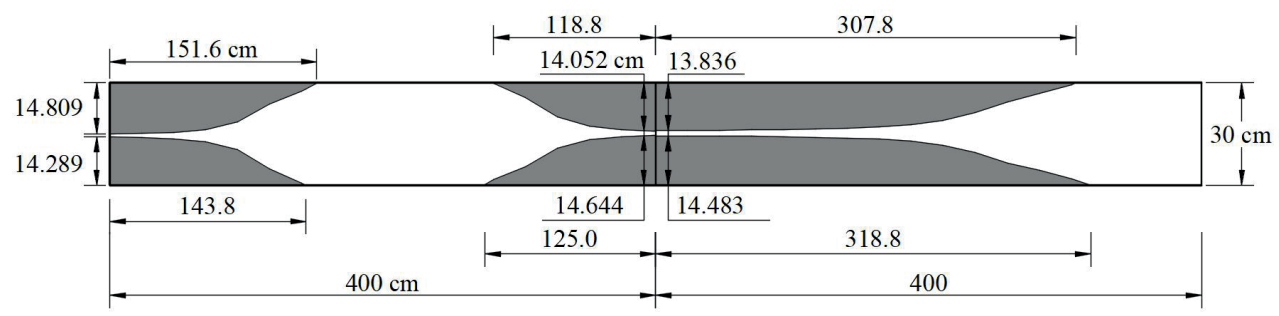

Fig. 11 Distribution of elastic and plastic zones in the beam

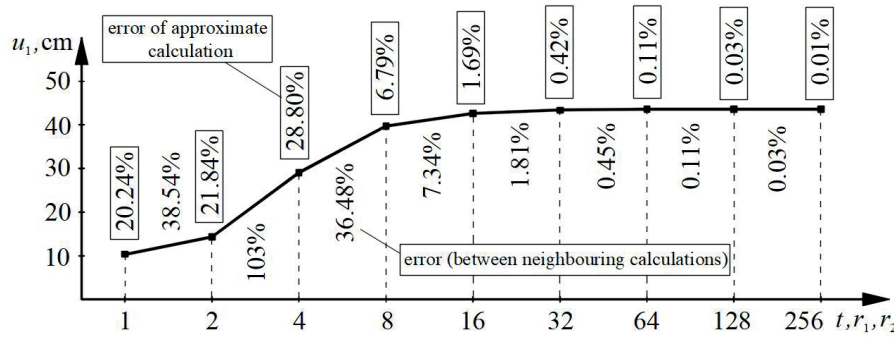

Fig. 12 Variation of displacement and error of displacement while simultaneously increasing the number of finite elements and load increments

Table 4 Main results of the numerical example

\begin{tabular}{|c|c|c|c|c|c|}
\hline$r_{k} / t$ & $u_{1}, \mathrm{~cm}$ & $M_{1}, \mathrm{kNm}$ & $\sigma_{\text {max }, 1}, \mathrm{MPa}$ & $u_{1}^{*}, \mathrm{~cm}$ & Calculation time \\
\hline $1 / 1$ & 10.3407 & -1220.9721 & 250.6762 & 8.5998 & $<1 \min \left(<1 \min ^{*}\right)$ \\
\hline $2 / 2$ & 14.3255 & -1267.4694 & 256.4700 & 17.4543 & $<1 \min \left(<1 \min ^{*}\right)$ \\
\hline $4 / 4$ & 29.0813 & -1202.9674 & 295.2400 & 37.4555 & $<1 \min \left(<1 \min ^{*}\right)$ \\
\hline $8 / 8$ & 39.6896 & -1166.8112 & 351.4875 & 42.3861 & $\sim 3 \min \left(<1 \min ^{*}\right)$ \\
\hline $16 / 16$ & 42.6040 & -1160.8554 & 372.7660 & 43.3246 & $\sim 8 \min \left(\sim 1 \min ^{*}\right)$ \\
\hline $32 / 32$ & 43.3741 & -1159.5057 & 381.9948 & 43.5582 & $\sim 23 \min \left(\sim 3 \min ^{*}\right)$ \\
\hline $64 / 64$ & 43.5699 & -1159.1653 & 386.3044 & 43.6161 & $\sim 84 \min \left(\sim 9 \mathrm{~min}^{*}\right)$ \\
\hline $128 / 128$ & 43.6189 & -1159.0794 & 388.3873 & 43.6305 & $\sim 270 \min \left(\sim 36 \mathrm{~min}^{*}\right)$ \\
\hline $256 / 256$ & 43.6317 & -1159.0622 & 389.4128 & 43.6346 & $\sim 17 \mathrm{~h}\left(\sim 150 \mathrm{~min}^{*}\right)$ \\
\hline
\end{tabular}

Explanations: ( )* - 'approximate' solution (when $\psi=0$ ); $\sigma_{\max }$ - maximum absolute value of normal stress in the cross section.

\subsection{Example 2}

In this example, the presented algorithm is applied for the analysis of a frame with linear hardening material model, and the results are compared to the solution of the elastic ideally plastic frame. A two story steel frame (Fig. 13a) with cross section parameters of $A_{1}=880 \mathrm{~cm}^{2}(0.44 \mathrm{~m} \times$ $0.2 \mathrm{~m}), A_{2}=480 \mathrm{~cm}^{2}(0.4 \mathrm{~m} \times 0.12 \mathrm{~m}), A_{3}=300 \mathrm{~cm}^{2}(0.3$ $\mathrm{m} \times 0.1 \mathrm{~m})$ and material properties $E=205 \mathrm{GPa}$ and $\sigma_{0}=$ $235 \mathrm{MPa}$ is considered. The analysis problem is solved for two cases: 1) $E_{h}=0$ (the material is elastic ideally plastic, - plasticity is concentrated at the nodes); 2) $E_{h}=E / 50$ (the material is linearly hardening and close to real carbon steel properties, - plasticity is distributed). The analysis results are shown in Figs. 13b and 14. These Figs. indicate that the plastic zones and plastic hinges coincide. The node displacements of the ideally plastic solution are 44-51\% larger than the hardening material model solution $\left(E_{h}=\right.$
$E / 50)$. For a qualitative comparison the same structure was modeled in COMSOL software using 3D FE and linear hardening material model (with $E_{h}=E / 50$ ) (Fig. 14a). Determined maximum horizontal displacement $(12.96 \mathrm{~cm})$ and plastic zone areas coincide with the results from the suggested methodology comparably well.

\section{Conclusions}

1. An algorithm for linearly hardening plane frame analysis based only on classical stress-strain state assumptions in a cross section was described. The proposed algorithm allows for the evaluation of plastic deformations along the length of an element and across the height of a cross section. Self-correcting internal iterations in the algorithm allows for the determining of accurate solutions which can be used to qualify other approximate methods. 


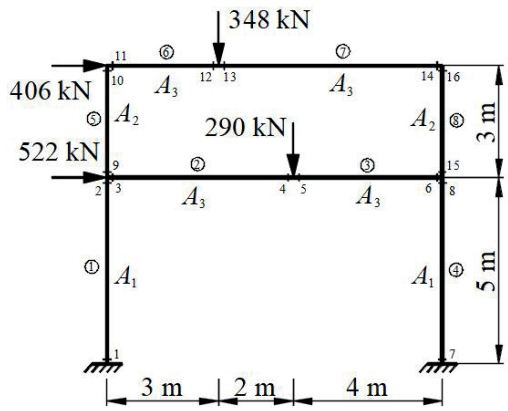

(a)

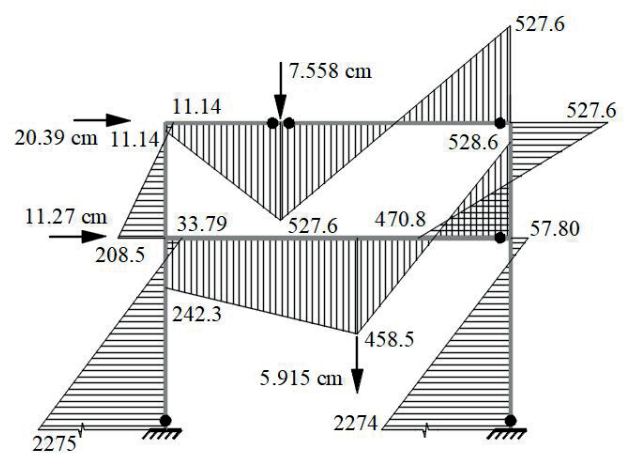

(b)

Fig. 13 (a) Frame model; (b) plastic hinges, bending moments and node displacements of the first analysis problem $\left(E_{h}=0\right)$

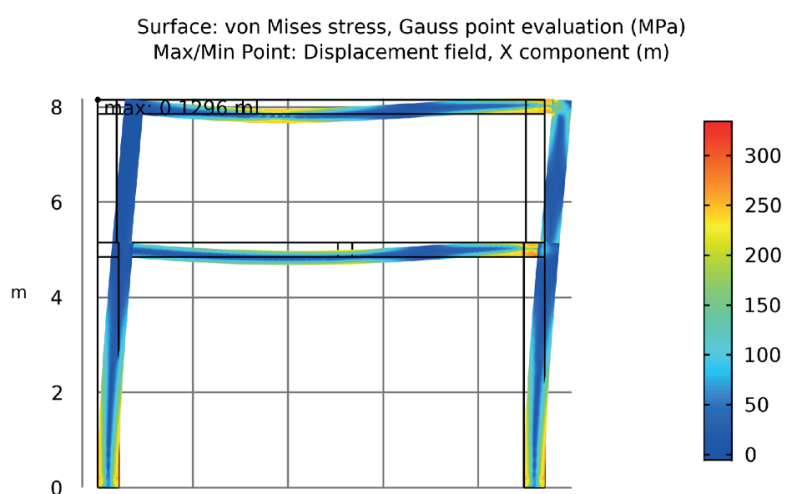

(a)

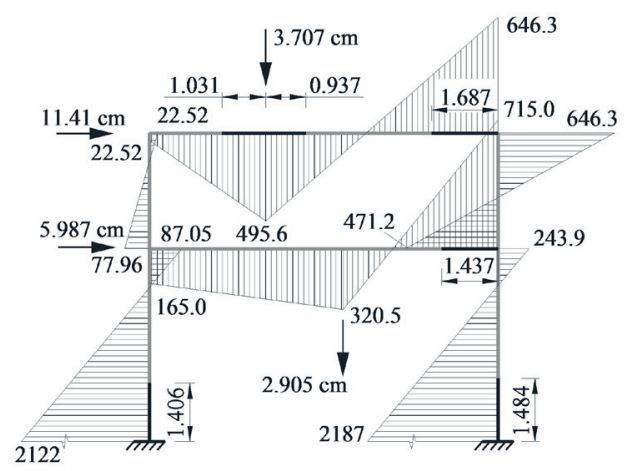

(b)

Fig. 14 (a) Deformed scheme, top beam displacement and von Mises stresses from COMSOL environment; (b) plastic zones, bending moments and node displacements of the second analysis problem
2. The proposed algorithm is suitable for implementation in a structural optimization problem, which is the current research topic of the paper's authors.

3. The numerical results (Example 1) indicate that it is sufficient to divide the structural elements into 16-32 finite elements and external loading into 16-32 increments to achieve reasonably accurate results. In addition, it shows that the 'accurate' solution method (when $\psi=1 / 3$ ) very slightly improves the accuracy of the results compared to the 'approximate' solution (when $\psi=0$ ): if $r_{1}=r_{2}=t=32$, the values of displacement $u_{1}$ differs only by $0.42 \%$ (Fig. 12). If the number of elements and/or load increments is further increased, the difference reduces even more. The computational time could be effectively reduced by applying the finite element grid of selective mesh.

4. The comparison of ideal elastic plastic $\left(E_{h}=0\right)$ and the linear hardening material $\left(E_{h}=E / 50\right)$ models shows that all the locations of the plastic deformations coincide, but the values of nodal displacements differ significantly: the first model gives $44-51 \%$ bigger displacements. This difference is due to the plastic hinge concept: the hinges form instantly in an entire section, while the linear hardening model allows for a gradual shift from elastic to plastic state and thus the stiffness of a structure reduces at a slower rate. Verification problem solved with COMSOL program using 3D mesh model gives $13.58 \%$ bigger top maximum horizontal displacement.

5. This publication describes a more academic - rectangular steel section analysis, nevertheless the presented methodology together with the previously published analytical equations [17] can be applied for the elastic-plastic stress-strain analysis of any cross-section.

\section{References}

[1] Byfield, M. P., Davies, J. M., Dhanalakshmi, M. "Calculation of the strain hardening behaviour of steel structures based on mill tests", Journal of Constructional Steel Research, 61(2), pp. 133-150, 2005. https://doi.org/10.1016/j.jcsr.2004.08.001

[2] Jaras, A, Kačianauskas, R. "The investigation of load carrying capacity of elastic-plastic strain hardening bisteel I-section beams", Journal of Civil Engineering and Management, 8(1), pp. 34-41, 2002.

https://doi.org/10.1080/13923730.2002.10531247

[3] Sawko, F. "Effect of strain hardening on the elasto-plastic behaviour of beams and grillages", Proceedings of the Institution of Civil Engineers, 28(4), pp. 489-504, 1964. https://doi.org/10.1680/iicep.1964.10015 
[4] Hoang, V.-L., Dang, H. N., Jaspart, J.-P., Demonceau J.-F. "An overview of the plastic-hinge analysis of 3D steel frames", Asia Pacific Journal on Computational Engineering, 2(1), 2015. https://doi.org/10.1186/s40540-015-0016-9

[5] Long, H. V., Hung, N. D. "Second-order plastic-hinge analysis of 3-D steel frames including strain hardening effects", Engineering Structures, 30(12), pp. 3505-3512, 2008. https://doi.org/10.1016/j.engstruct.2008.05.013

[6] Sekulovic, M., Nefovska-Danilovic, M. "Contribution to transient analysis of inelastic steel frames with semi-rigid connections", Engineering Structures, 30(4), pp. 976-989, 2008. https://doi.org/10.1016/j.engstruct.2007.06.004

[7] Izzuddin, B. A., Elnashai, A. S. "Adaptive space frame analysis. Part II: a distributed plasticity approach", Proceedings of the Institution of Civil Engineers - Structures and Buildings, 99(3), pp. 317-326, 1993 https://doi.org/10.1680/istbu.1993.24353

[8] Dulinskas, E. J., Zamblauskaitè, R., Zabulionis, D. "An Analysis of Elasto-Plastic Bar Cross-Section Stress-Strain State in a Pure Bending", In: 10th International Conference "Modern Building Materials, Structures and Techniques", Vilnius, Lithuania, 2010, pp. 599-603. [online] Available at: http://dspace.vgtu.lt/handle/1/481 [Accessed: 22.02.2019]

[9] Ghali, A., Neville, A. M., Brown, T. G. "Structural analysis: a unified classical and matrix approach", 6th ed., CRC Press, Boca Raton, Florida, United States, 2009.

[10] Moore, H. "MATLAB for Engineers", 5th ed., Pearson, London, United Kingdom, 2017.

[11] Atkočiūnas,J.,Merkevičiūtė,D.,Venskus,A.,Skaržauskas,V."Nonlinear programming and optimal shakedown design of frames", Mechanika, 64(2), pp. 27-33, 2007. [online] Available at: http://mechanika.ktu. lt/index.php/Mech/article/view/14789/ [Accessed: 22.02.2019]

[12] Blaževičius, G., Rimkus, L., Merkevičūtė, D., Atkočiūnas, J. "Shakedown analysis of circular plates using a yield criterion of the mean", Structural and Multidisciplinary Optimization, 55(1), pp. $25-36,2017$.

https://doi.org/10.1007/s00158-016-1460-z

[13] Atkočiūnas, J., Ulitinas, T., Kalanta, S., Blaževičius, G. "An extended shakedown theory on an elastic-plastic spherical shell", Engineering Structures, 101, pp. 352-363, 2015. https://doi.org/10.1016/j.engstruct.2015.07.021

[14] Palizzolo, L. "Optimization of continuous elastic perfectly plastic beams", Computers \& Structures, 82(4-5), pp. 397-411, 2004. https://doi.org/10.1016/j.compstruc.2003.10.015

[15] Kala, Z. "Global sensitivity analysis in stability problems of steel frame structures", Journal of Civil Engineering and Management, 22(3), pp. 417-424, 2016. https://doi.org/10.3846/13923730.2015.1073618

[16] Čyras, A. "Extreme principles and optimization problems for linearly strain hardening elastic-plastic structures", Applied Mechanics, 22, pp. 89-96, 1986. (in Russian)

[17] Grigusevičius, A., Blaževičius, G. "Numerical investigation of the elastic-plastic linear hardening stress-strain state of the frame element cross-section", Engineering Structures and Technologies, 8(3), pp. 94-100, 2016.

https://doi.org/10.3846/2029882X.2016.1217796
[18] Atkočiūnas, J. "Optimal Shakedown Design of Elastic-Plastic Structures", 1st ed., Vilnius Gediminas Technical University, Vilnius, Lithuania, 2011 https://doi.org/10.3846/1240-S

[19] Spiliopoulos, K., Weichert, D. "Direct Methods for Limit States in Structures and Materials", 1st ed., Springer, Dordrecht, Netherlands, 2014. https://doi.org/10.1007/978-94-007-6827-7

[20] Grigusevičius, A., Kalanta, S. "Optimization of elastic-plastic beam structures with hardening using finite element method", Foundations of civil and environmental engineering, 6, pp. 31-52, 2005. [online] Available at: http:/www.fcee.put.poznan.pl/sites/issues/2005.06/ full/fcee_2005-06_031-052.pdf [Accessed: 22.02.2019]

[21] Atkočiūnas, J., Karkauskas, R. "Optimization of elastic-plastic bar structures", VGTU, Vilnius, Lithuania, 2010. (in Lithuanian) https://doi.org/10.3846/1137-S

[22] Jirasek, M., Bazant, Z. P. "Inelastic Analysis of Structures", 1st ed., Wiley, Hoboken, New Jersey, United States, 2001.

[23] Kalanta, S. "Finite Elements for Modelling Beams Affected by a Distributed Load", Statyba, 5(2), pp. 91-99, 1999. (in Russian) https://doi.org/10.1080/13921525.1999.10531442

[24] Lógó, J., Movahedi Rad, M. Knabel, J., Tauzowski, P. "Reliability based design of frames with limited residual strain energy capacity", Periodica Polytechnica Civil Engineering, 55(1), pp. 13-20, 2011. https://doi.org/10.3311/pp.ci.2011-1.02

[25] Movahedi Rad, M., Lógó, J. "Plastic behavior and stability constraints in the reliability based shakedown analysis and optimal design of skeletal structures", Asian Journal of Civil Engineering (Building and Housing), 12(4), pp. 395-413, 2011.

[26] Movahedi Rad, M. "A Review of Elasto-Plastic Shakedown Analysis with Limited Plastic Deformations and Displacements", Periodica Polytechnica Civil Engineering, 62(3), pp. 812-817, 2018 https://doi.org/10.3311/PPci.11696 
Appendix A

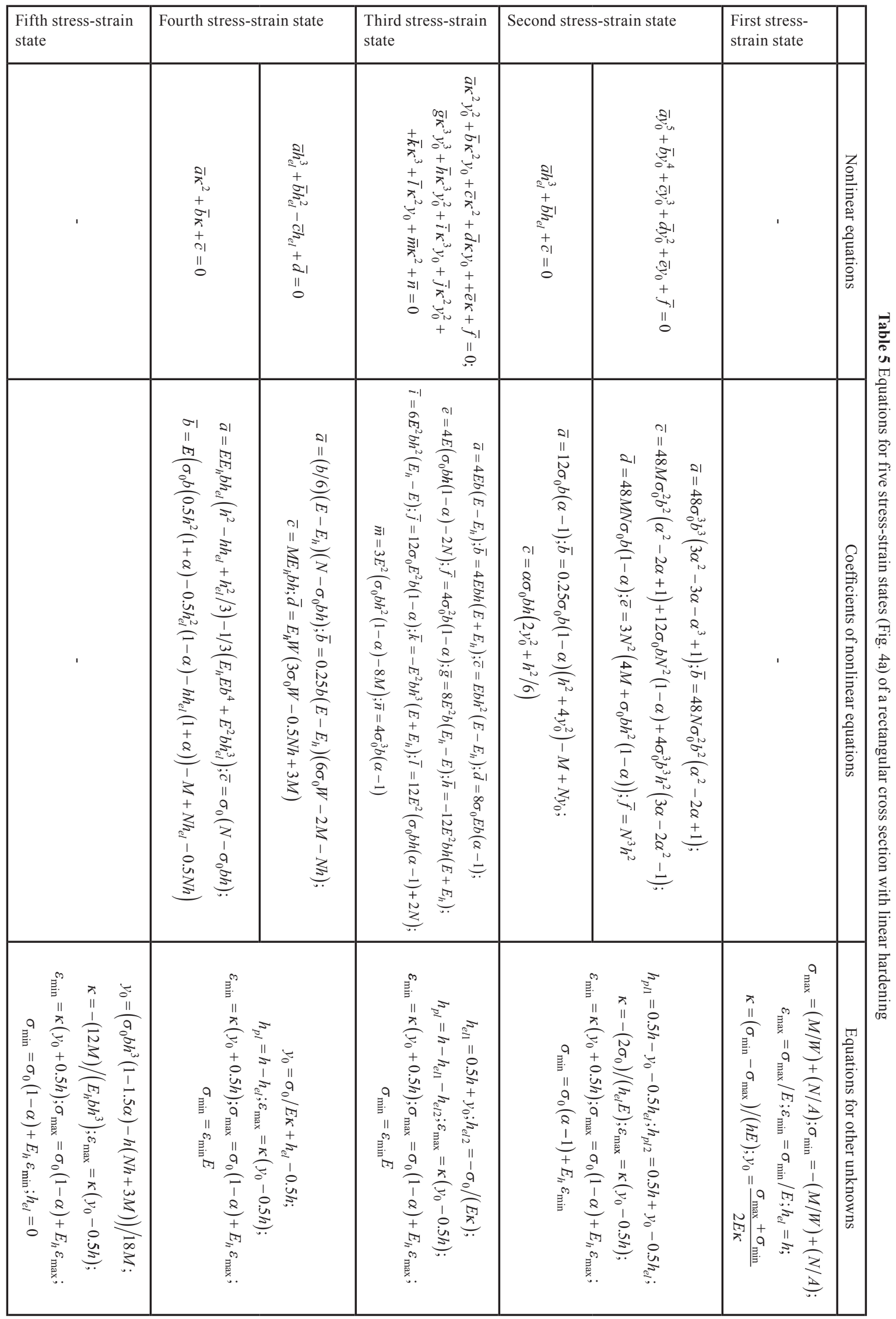

